\title{
Surgical treatment of pseudoaneurysm of right coronary artery with CABG in Dr Sirajul Islam medical college hospital
}

\begin{abstract}
Background: Post-PCI coronary pseudoaneurysm is a rare but critical scenario in cardiovascular field. Proper and prompt decision with skilled surgical team is needed for good result.

Methods and materials: A 47 years old man with the history of percutaneous coronary intervention (PCI) in LAD and RCA in July 2018 came to our hospital on 09/12/18 with chest pain, palpitation, respiratory distress on exertion. On Echocardiogram Mild Regional Wall Motion Abnormality (RWMA) seen with LVEF 42\%, other parameters were in normal range. On CAG Pseudoanurysm was seen in RCA (Previously stented). Surgical intervention was done with cardiopulmonary bypass (CPB). After Sternotomy, severe pericardial adhesion had been seen, adhesion was very carefully dissected, pseudoaneurysm was opened, palpated the stent on RCA, RCA stent had been removed, endarterectomy was done in RCA distal to pseudoaneurysm, 2 small perforation in RCA was repaired by 6-0 polypropylene, RCA proximally and distally ligated with 4-0 polypropylene. Pseudoaneurysm had been removed and marsupialization was done. Venous graft was given to distal RCA after long endarterectomy.
\end{abstract}

Result: Post- operative period was uneventful. The patient was discharged on $8^{\text {th }}$ post operative day in good general condition and he is doing well in our regular follow up.

Conclusion: Post-PCI coronary pseudoaneurysm occurs rarely. Surgical repair gives good outcome.

Keywords: coronary angiogram, thrombosis, embolization, cardiac tamponade, obesity, dyslipidemia, hypertension, coronary artery disease
Volume I3 Issue 4 - 2020

\section{Mehdi Hasan Mazumder, Rajib Kumar Basak, Nazmul Hossain, Nuruddin Mohammod Zahangir \\ Department of Cardiovascular and Thoracic Surgery, Dr Sirajul Islam Medical College \& Hospital, Bangladesh}

\section{Correspondence: Nuruddin Mohammod Zahangir, Chie Cardiac Surgeon and Senior Consultant, Department of Cardiovascular and Thoracic Surgery, Dr Sirajul Islam Medical College \& Hospital, Bangladesh, Fax +88029343018, Tel +8801818031063,Email nmzaha@yahoo.com}

Received: May I5, 2020 | Published: August 24, 2020
Abbreviations: PCI, percutaneous coronary intervention; RWMA, regional wall motion abnormality; $\mathrm{CPB}$, cardiopulmonary bypass

\section{Background}

Post percutaneous coronary intervention peudoaneurysm formation is a rarely reported phenomenon. Pseudoaneurysms, of course, can lead to some adverse outcomes as thrombosis with distal embolization, rupture, and cardiac tamponade. Herein, we describe the case of a patient who experienced pseudoaneurysm formation after deployment of a stent.

\section{Methods and materials}

A 47years old man presented post PCI (2 stented, RCA and LAD, July 2018) with unstable angina after 4 months history of exertional chest pain, palpitation, respiratory distress on exertion on 09/12/18. His medical history included obesity, dyslipidemia, hypertension, smoking, and a significant family history of early-onset coronary artery disease.

On Echocardiogram Mild RWMA seen with LVEF 42\%, other parameters were in normal range. Coronary Angiogram revealed a focal stenosis in the proximal RCA and Pseudoanurysm was seen in RCA (Previously stented).

The patient was having recurrent chest pain 2 month after the initial percutaneous coronary intervention (PCI), and he was taken for repeat coronary angiography on the day admission. The RCA stent was occluded. However, just outside of the mid-portion of the stent was collection of contrast, which appeared to reveal a pseudoaneurysm.

Surgical intervention was done with cardiopulmonary bypass. After Sternotomy, severe dense pericardial adhesion had been seen around the pseudoaneurysdm, adhesion was very carefully dissected, pseudoaneurysm was opened, palpated the stent on RCA, stent had been removed, endarterectomy was done in RCA distal to pseudoaneurysm, 2 small perforation in RCA was repaired by 6-0 polypropylene, RCA proximally and distally ligated with 4-0 polypropylene. Most of the wall of the Pseudoaneurysm had been removed and marsupialization was done. Venous graft was given to distal RCA after long endarterectomy (Figures 1-7).

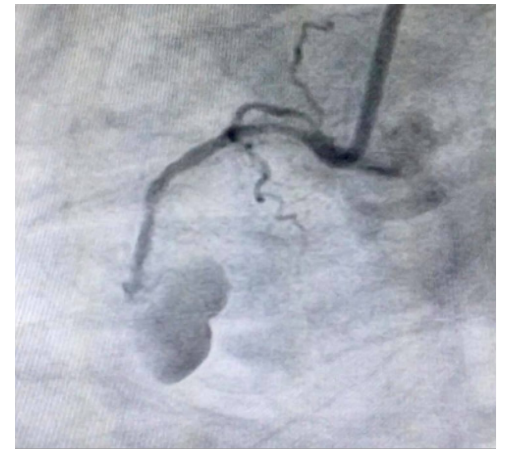

Figure I Pseudoaneurysm in RCA (CAG). 


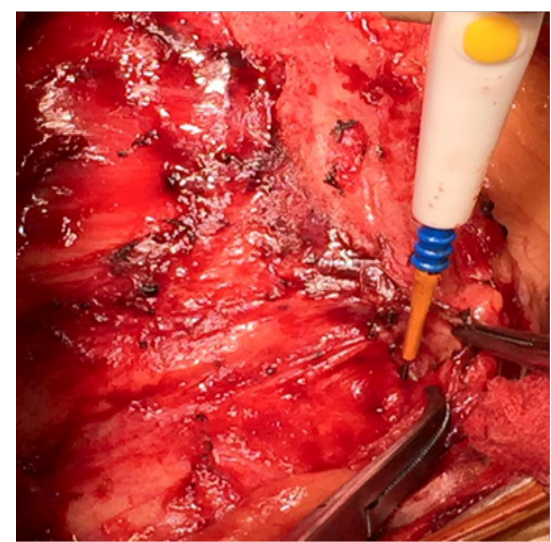

Figure 2 Severe pericardial adhesions.

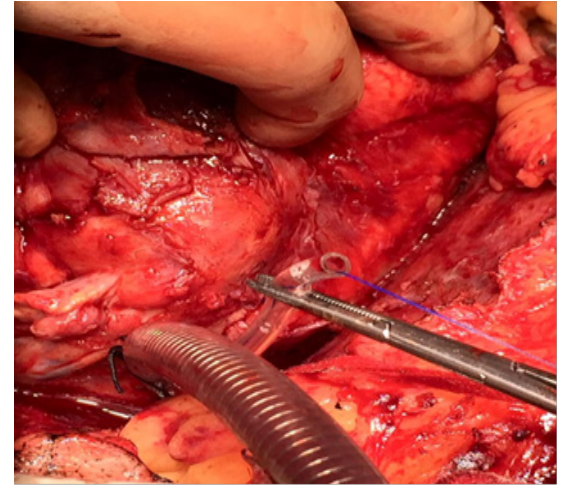

Figure 3 Pseudoaneurysm in right coronary artery.

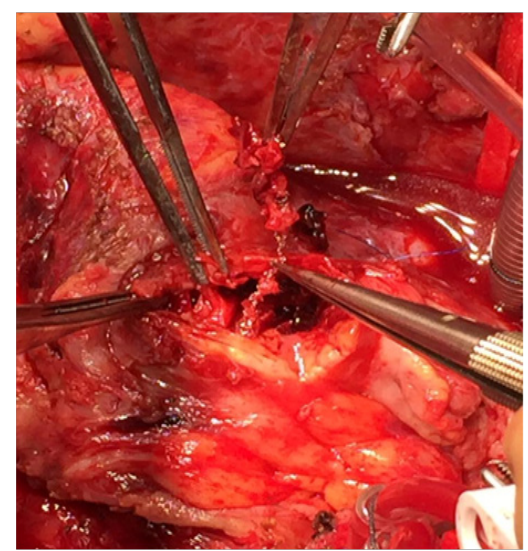

Figure 4 Pseudoaneurysm opened and removal of stent.

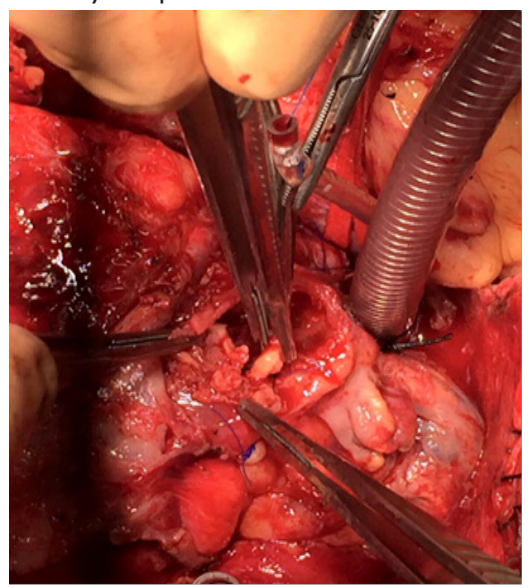

Figure $\mathbf{5}$ Endarterectomy from proximal and distal coronary artery.

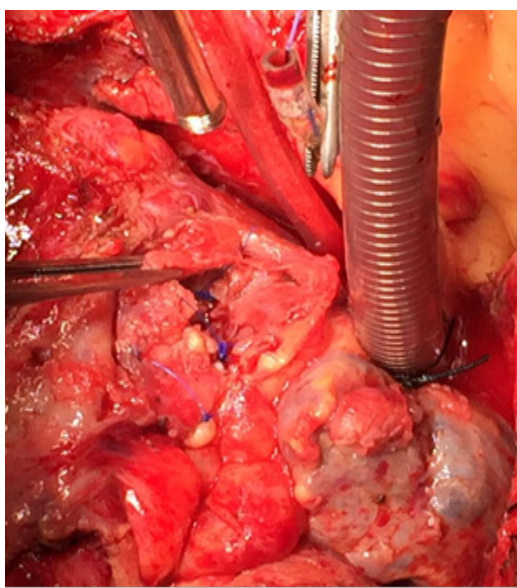

Figure 6 Ligation of proximal and distal coronary artery.

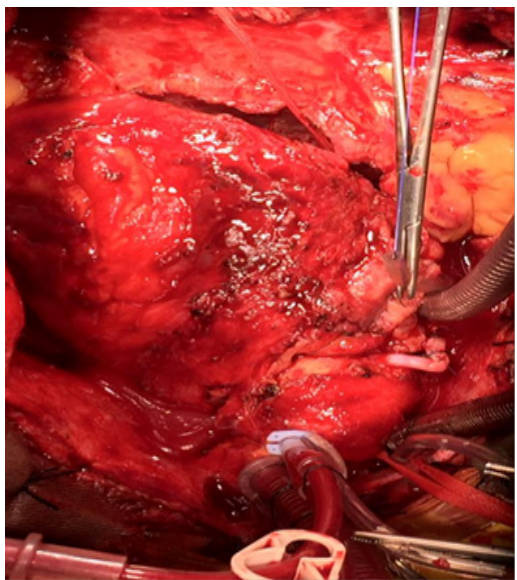

Figure 7 Venous grafts from aorta to distal RCA after in Pseudoaneurysm endarterectomy.

\section{Result}

Post- operative period was uneventful. The patient was discharged on $8^{\text {th }}$ post operative day in good general condition. Regular follow up had been done. No significant problem was found.

\section{Discussion}

Due to the inherent limitations of coronary angiography, pseudoaneurysms that form after PCI are usually overlooked, or they are misdiagnosed as true aneurysms. ${ }^{1}$ Only a few cases have been reported. ${ }^{2}$ The incidence of formation of coronary artery aneurysms is $2 \%$ to $10 \%$ after PCI. ${ }^{3}$ Pseudoaneurysm formation is more commonly a result of traumatic rupture or deep-vessel injury of an artery. The fibrous wall of a pseudoaneurysm forms a continuum with the structure of the adjacent vascular wall but lacks of 1 or more of the wall's vascular layers. It has been found that pseudoaneurysms can progressively enlarge and rupture. ${ }^{4}$

The prevalence of coronary-artery pseudoaneurysms in cases undergoing coronary angiography is reportedly $0.2-10 \%$. Such pseudoaneurysms occurred in the right coronary artery, left anterior descending branch, left circumflex branch, and left main trunk in $40.4 \%, 32.3 \%, 23.4 \%$, and 3.5\%, respectively, of all cases. Most cases are asymptomatic. ${ }^{5}$ Coronary-artery pseudoaneurysms can have a wide variety of causes. The present case is believed to be iatrogenic because the RCA readily experienced vascular-wall damage from catheters and guide wires. The morphology was saccular for this pseudoaneurysm. The pseudoaneurysm formed after PCI in July 
2018, and the patient's medical history did not include other diseases that could induce it. The incidence of iatrogenic coronary artery pseudoaneurysms during catheter examination or treatment is approximately $0.1 \%$, and RCA lesions occur in approximately $0.07 \%$ of cases. It occurs more frequently with percutaneous coronary angioplasty, and twice as often with coronary angi-ography. ${ }^{6}$ Causes include anatomical anomalies in the coronary artery, atherosclerosis, rapidly injected contrast agent, catheter type (it is significantly more frequent with left Amplatz guiding catheters), improper catheter placement, and deep engagement during balloon drawing. ${ }^{7-10}$ Our case was a large pseudoaneurysm as observed in coronary angiogram, so we did surgical correction for it.

\section{Conclusion}

Coronary artery pseudoaneurysm is a rare entity and is being seen more frequently with the increasing use of stents during angioplasty. Proximal ligation and placation of the aneurysm with coronary artery bypass grafting provided good results. ${ }^{11}$ Skilled and experienced surgical team is very essential for good outcome.

\section{Acknowledgments}

None.

\section{Conflicts of interest}

Author declares that there are no conflicts of interest.

\section{Funding}

None.

\section{References}

1. Aqel RA, Zoghbi GJ, Iskandrian AE. Spontaneous coronary artery dissection with pseudoaneurysm formation diagnosed by intravascular ultrasound: a case report. Echocardiography. 2004;21(2):153-157.
2. Berkalp B, Kervancioglu C, Oral D. Coronary artery aneurysm formation after balloon angioplasty and stent implantation. Int J Cardiol. 1999;69(1):65-70.

3. Slota PA, Fischman DL, Savage MP, et al. Goldberg S. Frequency and outcome of development of coronary artery aneurysm after intracoronary stent placement and angioplasty. STRESS Trial Investigators. Am $J$ Cardiol. 1997;79(8):1104-1106.

4. Regar E, Klauss V, Henneke KH, et al. Coronary aneurysm after bailout stent implantation: diagnosis of a false lumen with intravascular ultrasound. Cathet Cardiovasc Diagn. 1997;41(4):407-410.

5. Mata KM, Fernandes CR, Floriano EM, et al. Coronary artery aneurysms: an update. In: Lakshmanadoss U, editor. Novel strategies in ischemic heart disease. 2012.

6. Eshtehardi P, Adorjan P, Togni M, et al. Iatrogenic left main coronary artery dissection: incidence, classification, management, and long-term follow-up. Am Heart J. 2010;159(6):1147-1153.

7. Awadalla H, Sabet S, El Sebaie A, et al. Catheter-induced left main dissection incidence, predisposition and therapeutic strategies experience from two sides of the hemisphere. J Invasive Cardiol. 2005;17(4):233236.

8. Onsea K, Kayaert P, Desmet W, et al. Iatrogenic left main coronary artery dissection. Neth Heart J. 2011;19(4):192-195.

9. Kovac JD, de Bono DP. Cardiac catheter complications re-lated to left main stem disease. Heart. 1996;76(1):76-78.

10. Slack JD, Pinkerton CA, VanTassel JW, et al. Left main coronary artery dissection during percutaneous transluminal coro-nary angioplasty. Cathet Cardiovasc Diagn. 1986;12(4):255-260.

11. Singh SK, Goyal T, Kumar S. Surgical treatment for coronary artery aneurysm: a single-centre experience. Interact Cardiovasc Thorac Surg. 2013;17(4):632-636. 